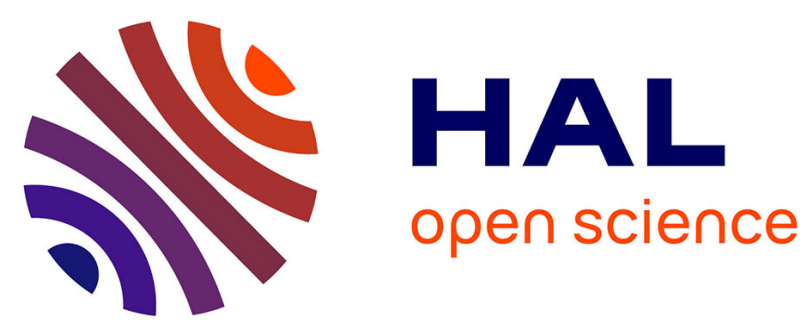

\title{
Ventilatory responses at submaximal exercise intensities in healthy children and adolescents during the growth spurt period: a semi-longitudinal study
}

Fenfen Zhou, Xiaojian Yin, Kilian Phillipe, Aya Houssein, Steven Gastinger, Jacques Prioux

\section{To cite this version:}

Fenfen Zhou, Xiaojian Yin, Kilian Phillipe, Aya Houssein, Steven Gastinger, et al.. Ventilatory responses at submaximal exercise intensities in healthy children and adolescents during the growth spurt period: a semi-longitudinal study. European Journal of Applied Physiology, 2021, 121 (11), pp.3211-3223. 10.1007/s00421-021-04776-4 . hal-03332001

\section{HAL Id: hal-03332001 \\ https://hal.science/hal-03332001}

Submitted on 16 Sep 2021

HAL is a multi-disciplinary open access archive for the deposit and dissemination of scientific research documents, whether they are published or not. The documents may come from teaching and research institutions in France or abroad, or from public or private research centers.
L'archive ouverte pluridisciplinaire HAL, est destinée au dépôt et à la diffusion de documents scientifiques de niveau recherche, publiés ou non, émanant des établissements d'enseignement et de recherche français ou étrangers, des laboratoires publics ou privés. 


\title{
2 Ventilatory responses at submaximal exercise intensities in healthy children 3 and adolescents during the growth spurt period: a semi-longitudinal study
}

\author{
Fenfen Zhou ${ }^{1,2,3} \cdot$ Xiaojian Yin $^{1} \cdot$ Kilian Phillipe $^{4} \cdot$ Aya Houssein $^{2,3} \cdot$ Steven Gastinger ${ }^{5,6} \cdot$ Jacques Prioux $^{2,3}$ \\ Received: 15 June 2020 / Accepted: 19 July 2021 \\ (๑) The Author(s), under exclusive licence to Springer-Verlag GmbH Germany, part of Springer Nature 2021
}

\begin{abstract}
Purpose To identify the changes of ventilation $\left(\dot{\mathrm{V}}_{\mathrm{E}}\right)$, tidal volume $\left(\mathrm{V}_{\mathrm{T}}\right)$ and respiratory frequency $(\mathrm{fr})$ at different incremental step test intensities during maturation of children and adolescents.

Methods A semi-longitudinal study was conducted on 68 healthy untrained boys and girls aged 11-17 years. The subjects were separated into three distinct age groups. $\dot{\mathrm{V}}_{\mathrm{E}}, \mathrm{V}_{\mathrm{T}}$ and fr parameters were evaluated annually during 3 years by modifying incremental step test intensities according to ventilatory threshold $\left(\mathrm{V}_{\mathrm{Th}}\right)$ level $\left(30,60\right.$ and $90 \%$ of $\left.\mathrm{VO}_{2 \max }\right)$. Absolute and relative values of ventilatory responses were analyzed and compared according to age and developmental phase.

Results (1) Height, weight, lean body mass and vital capacity increased significantly from 11 to 17 years of age. (2) $\dot{\mathrm{VO}}_{2 \max }$, $\dot{\mathrm{V}}_{\mathrm{E}}$, and $\mathrm{V}_{\mathrm{T}}$ increased during maturation even when exercise intensity changed, especially from 11 to 15 years of age. On the other hand, fr showed a decreasing trend.

Conclusion Increases of $\mathrm{V}_{\mathrm{T}}$ are the main reason for $\dot{\mathrm{V}}_{\mathrm{E}}$ increases during maturation of children. fr decreased independently of total body mass during maturation. $\dot{\mathrm{V}}_{\mathrm{E}} \cdot \mathrm{kg}^{-1}$ was stable despite intensity variations. $\mathrm{V}_{\mathrm{T}} \cdot \mathrm{kg}^{-1}$ increased significantly from 11 to 15 years then stabilized at 17 years. Lean body mass seems to explain the evolution of $\mathrm{V}_{\mathrm{T}} \cdot \mathrm{kg}^{-1}$ during maturation.
\end{abstract}

Keywords Semi-longitudinal study $\cdot$ Submaximal exercise $\cdot$ Breathing pattern $\cdot$ Children · Adolescents $\cdot$ Boys $\cdot$ Girls

Communicated by Susan Hopkins.

Fenfen Zhou

fenfenzhou3@gmail.com

1 Sino-French Joint Research Center of Sport Science, College of Physical Education and Health, East China Normal

University, Shanghai, China

2 Laboratoire Mouvement, Sport, Santé (EA 7470), Université de Rennes, 2, Avenue Robert Schuman, 35170 Bruz, France

3 Département Sciences du Sport et Éducation Physique, Ecole Normale Supérieure de Rennes, Campus de Ker Lann, Avenue Robert Schuman, 35170 Bruz, France

4 Laboratory of Movement, Balance, Performance and Health (MEPS, EA-4445), University of Pau and Pays de l'Adour, Tarbes, France

5 Laboratoire Mouvement, Sport, Santé (EA 1274), Université de Rennes 2, Bruz, France

6 APCoSS, Institut de Formation en Education Physique et en Sport d'Angers, (IFEPSA), Les Ponts de Cé, France

$\begin{array}{ll}\text { Abbreviations } \\ \mathrm{BM} & \text { Total body mass } \\ \mathrm{CO}_{2} & \text { Carbon dioxide } \\ \mathrm{fr} & \text { Respiratory frequency } \\ \mathrm{fr}_{\text {max }} & \text { Maximal respiratory frequency } \\ \mathrm{HR} & \text { Heart rate } \\ \mathrm{O}_{2} & \text { Oxygen } \\ \mathrm{R} & \text { Respiratory exchange ratio } \\ \mathrm{T}_{\mathrm{E}} & \text { Expiratory time } \\ \mathrm{T}_{\mathrm{Emax}} & \text { Maximal expiratory time } \\ \mathrm{T}_{\mathrm{I}} & \text { Inspiratory time } \\ \mathrm{T}_{\mathrm{Imax}} & \text { Maximal inspiratory time } \\ \mathrm{T}_{\mathrm{TOT}} & \text { Total respiratory time } \\ \mathrm{T}_{\mathrm{TOT}} & \text { Maximal total respiratory time } \\ \mathrm{T}_{\mathrm{TOTmax}} & \text { Maximal total respiratory time } \\ \mathrm{VC}_{\mathrm{C}} & \text { Vital capacity } \\ \dot{\mathrm{V}}_{\mathrm{CO}} & \text { Respiratory dioxide output } \\ \dot{\mathrm{V}}_{\mathrm{E}} & \text { Ventilation } \\ \dot{\mathrm{V}}_{\mathrm{Emax}} & \text { Maximal ventilation } \\ \dot{\mathrm{V}}_{2} & \text { Oxygen uptake } \\ \dot{\mathrm{VO}}_{2 \max } & \text { Maximal oxygen uptake } \\ \mathrm{V}_{\mathrm{T}} & \text { Tidal volume } \\ & \end{array}$


Maximal tidal volume

$5 \quad \mathrm{~V}_{\mathrm{Th}}$

Ventilatory threshold

\section{Introduction}

The increased supply of oxygen $\left(\mathrm{O}_{2}\right)$ to the muscles is essential during physical exercise (Zhang et al. 1993). During the first phase of this process, is the transport of $\mathrm{O}_{2}$ to the alveoli through ventilation $\left(\dot{\mathrm{V}}_{\mathrm{E}}\right.$ ) (Calbet and Lundby 2009). $\dot{\mathrm{V}}$ $\mathrm{E}$, expressed in liters per minute $\left(1 . \mathrm{min}^{-1}\right)$, corresponds to the volume of air mobilized per minute, resulting from the product of the tidal volume $\left(\mathrm{V}_{\mathrm{T}}\right)$ by the respiratory frequency (fr) (Holley et al. 2016). $\dot{\mathrm{V}}_{\mathrm{E}}$ must adapt at each level of exercise intensity to the needs of $\mathrm{O}_{2}$ in muscles. $\dot{\mathrm{V}}_{\mathrm{E}}$ is also regulated to remove carbon dioxide $\left(\mathrm{CO}_{2}\right)$ from the blood to maintain normocapnia (Whipp and Pardy 1986). Any failure of this adaptation will result in physical performance limitations and discomfort during exercise (O’Donnell et al. 2009).

Numerous studies have shown that metabolic and anthropometric changes during puberty will have an influence on ventilatory response at maximal exercise $\left(\dot{\mathrm{V}}_{\text {Emax }}\right)$ in boys (Rutenfranz et al. 1981; Prioux et al. 1997; Burstein et al. 2020; Armstrong and Welsman 2020) and girls (Rutenfranz et al. 1981; Rowland and Cunningham 1997; Burstein et al. 2020; Armstrong and Welsman 2020). Several studies (Robinson 1938; Andersen et al. 1974; Rutenfranz et al. 1981; Boule et al. 1989; Armstrong et al. 1997; Rowland and Cunningham 1997; Ondrak and McMurray 2006; Marinov et al. 2007) have also analyzed the changes in ventilatory response at submaximal intensities during puberty. Nevertheless, only two of these studies are of longitudinal aspect (Rowland and Cunningham 1997; Rutenfranz et al. 1981) whereas the others are cross-sectional studies. However, the cross-sectional studies did not consider differences in physical maturation among subjects of the same chronological age (Matecki et al. 2003). Consequently, cross-sectional values give only the range of variability at a certain age and do not provide a true reference for the dynamic process of growth (Rutenfranz et al. 1981). Therefore, longitudinal studies can be expected to provide a clearer picture in changes of ventilatory response at submaximal exercise intensities compared to cross-sectional studies (Rowland and Cunningham 1997). Furthermore, among the two remaining longitudinal studies, Rowland and Cunningham, (1997) compared ventilatory responses according to age at absolute exercise intensities (walking speed: $3.25 \mathrm{mph}$ ) rather than relative exercise intensities. However, the absolute values did not consider the children's evolution of physical fitness with the age parameter. Indeed, the same intensity, expressed in absolute value, may result in greater ventilatory responses in younger and smaller subjects when compared to the older and larger participants (Ondrak and McMurray 2006). Finally, Rutenfranz et al. (1981) have studied the ventilatory response during a maximal incremental step test performed on a cycle ergometer using relative intensities which varied between 50 and $70 \%$ of $\mathrm{VO}_{2 \max }$. However, the choice of these exercise intensities is never justified by the authors. To date, no longitudinal studies have analyzed the ventilatory response during exercise in children and adolescents at exercise intensities determined by ventilatory threshold $\left(\mathrm{V}_{\mathrm{Th}}\right)$. Nevertheless, it is well known that ventilatory responses differ according to relative exercise intensity and particularly as a function of $\mathrm{V}_{\mathrm{Th}}$ (Prado et al. 2010). Indeed, during the first minutes of a maximal incremental test, during which the power increases every minute, $\dot{\mathrm{V}}_{\mathrm{E}}$ increases proportionally to the metabolic rate determined by the oxygen uptake $\left(\mathrm{V}_{2}\right)$ and/or carbon dioxide output $\left(\dot{\mathrm{V}} \mathrm{CO}_{2}\right)$ measurements. When exercise intensity exceeds an average of $50-60 \%$ of $\dot{\mathrm{VO}}_{2 \max }$, which corresponds to the $\mathrm{V}_{\mathrm{Th}}$, the increase in $\dot{\mathrm{V}}_{\mathrm{E}}$ accelerates while $\dot{\mathrm{V}} \mathrm{O}_{2}$ continues to increase linearly with exercise intensity (Wasserman et al. 1967). A second non-linear increase in $\dot{\mathrm{V}}_{\mathrm{E}}$ is observed when the metabolic rate reaches approximately $80-90 \%$ of the subject's $\dot{\mathrm{VO}}_{2 \max }$. At this point, $\dot{\mathrm{V}}_{\mathrm{E}}$ increases disproportionately to $\dot{\mathrm{VO}}_{2}$ and $\dot{\mathrm{VCO}}_{2}$ (Wasserman et al. 1986). Our semi-longitudinal study, covering a total age range of 11-17 years in boys and 11-15 years in girls, is, therefore, in line with that of Rutenfranz et al (1981). Its objective was thus to further specify the changes with maturation of submaximal ventilatory response during a maximal incremental step test. To do so, we compared the ventilatory responses according to age at three exercise intensities chosen according to $\mathrm{V}_{\mathrm{Th}}$ measured during a maximal incremental step test, i.e., under $\mathrm{V}_{\mathrm{Th}}$ corresponding to $30 \%$ of $\dot{\mathrm{VO}}_{2 \max }$, around $\mathrm{V}_{\mathrm{Th}}$ corresponding to $60 \%$ of $\dot{\mathrm{VO}}_{2 \max }$ and above $\mathrm{V}_{\mathrm{Th}}$ corresponding to $90 \%$ of $\dot{\mathrm{VO}}_{2 \max }$.

\section{Materials and methods}

\section{Subjects}

Fifty-eight healthy untrained boys $(n=54)$ and girls $(n=14)$ started in this study. None of them had ever taken part in $\mathbf{A Q 4}$ ?0 training or athletic competition. Time spent in extracur- 131 ricular physical activities was between $2 \mathrm{~h} 49 \mathrm{~min} \pm 0.32$ and 132 $4 \mathrm{~h} 28 \mathrm{~min} \pm 0.67$ per week for the boys (Table 1 ) and between $2 \mathrm{~h} 34 \mathrm{~min} \pm 0.44$ and $4 \mathrm{~h} 18 \mathrm{~min} \pm 1.18$ for the girls (Table 2). 134 Annually, at the same period and for 3 years, the children 135 performed a maximal incremental step test on a bicycle ergometer in their school. Five different age groups were established with an initial age for boys of $11.2 \pm 0.50$ years (group I $-n=22$ ), $12.9 \pm 0.71$ years (group II $-n=18$ ), and $14.9 \pm 0.75$ years (group III $-n=14$ ). Concerning girls, the initial age was of $11.2 \pm 0.61$ years (group IV $-n=7$ ), and $12.9 \pm 1.11$ years (group $\mathrm{V}-n=7$ ). Concerning boys, 


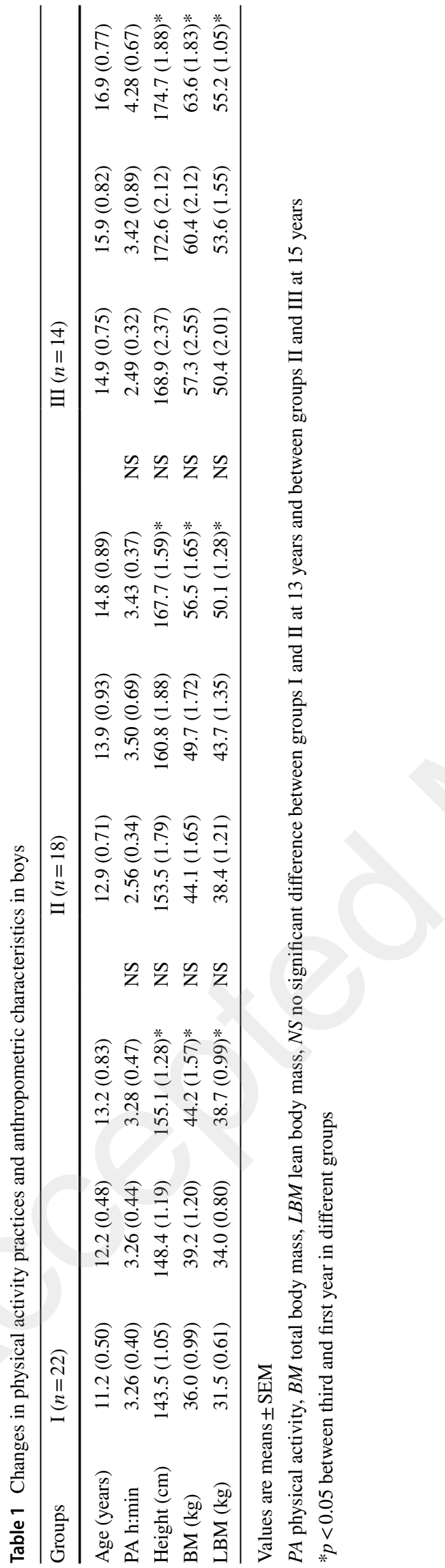

the children in group I were tested from $11.2 \pm 0.50$ to $13.2 \pm 0.83$ years, children in group II from $12.9 \pm 0.71$ to $14.8 \pm 0.89$ years and children in group III from $14.9 \pm 0.75$ to $16.9 \pm 0.77$ years. Concerning girls, the children in group IV were tested from $11.2 \pm 0.61$ to $13.0 \pm 0.57$ and children in group V from $12.9 \pm 1.11$ to $14.9 \pm 1.72$. Subjects and their parents provided informed consent following an explanation of the study's procedures and objectives. The study protocol was approved by the hospital's ethics committee.

\section{Measurements}

Anthropometric measurements: the following measurements were performed: total body mass (BM), height and skinfold thickness (bicipital, tricipital, subscapular and supra-iliac). All measurements were taken by the same observer according to technique and positions established by the International Biological Program (Weiner and Lourie 1981). Body fat mass was assessed from four skinfold thickness measurements according to Durnin and Rahaman (1967). Lean body mass (LBM) was calculated by subtracting body fat mass from $\mathrm{BM}$.

Stage of development: the same pediatrician assessed the level of pubertal maturation by analyzing pubic hair growth according to Tanner's five stages (Tanner 1962). The three age groups corresponded to three maturational groups: prepubertal, stage I (groups I and IV), pubertal, stages II and III (groups II and V) and post-pubertal, stages IV and V (group III). In this classification, stage 1 represents the immature, prepubertal state, while stage 5 represents fully matured adolescence.

Gas exchange measurements: a nose clip and a buccal piece were attached to subjects. During exercise, the subjects breathed through a low-resistance valve (Warren E. Collins, Inc., Mass., USA) attached to a large tubing (i.d. $3.5 \mathrm{~cm}$ ) into a $5 \mathrm{~L}$ mixing chamber. Inspiratory airflow was measured with a Fleisch no. 3 pneumotachometer (Godard, Statham, Hollande) and a pressure transducer (MP 45, Vali-A dyne, Engineering Corp., Calif., USA) with a measuring range of $\pm 2 \mathrm{cmH}_{2} \mathrm{O}$. The pneumotachograph was placed on the inspiratory line to avoid problems linked to water vapor. Calibration of the flow module was accomplished by introducing a measured volume of air for several flows. Expired gases were sampled in the mixing box and analyzed for oxygen $\left(\mathrm{O}_{2}\right)$ with a polarographic analyzer (OM 11, Sensormedics Corp., Calif., USA). Carbon dioxide $\left(\mathrm{CO}_{2}\right)$ was analyzed with an infrared analyzer (Diamant 6000, Cosma, France). Gas analyzers were calibrated before and after each test with standard gases. Inspiratory flow and fractions of expired $\mathrm{O}_{2}$ and $\mathrm{CO}_{2}$ were treated by a computer that calculated the following parameters from 10 breathing cycles: $\dot{\mathrm{V}}_{\mathrm{E}}, \mathrm{V}_{\mathrm{T}}$, fr, $\dot{\mathrm{V}}$ $\mathrm{O}_{2}$ and $\dot{\mathrm{V} C O} \mathrm{O}_{2}$. 
Table 2 Changes in physical activity practices and anthropometric characteristics in girls

\begin{tabular}{lrrrrrrr}
\hline Groups & IV $(n=7)$ & \multicolumn{7}{c}{$\mathrm{V}(n=7)$} \\
\hline Age (years) & $11.2(0.61)$ & $12.2(0.81)$ & $13.0(0.57)$ & & $12.9(1.11)$ & $13.9(1.11)$ & $14.9(1.72)$ \\
PA h:min & $3.48(1.10)$ & $4.12(1.06)$ & $4.18(1.18)$ & $\mathrm{NS}$ & $3.30(0.72)$ & $2.34(0.44)$ & $3.0(0.68)$ \\
Height (cm) & $148.7(2.44)$ & $154.6(2.25)$ & $158.1(2.09) *$ & $\mathrm{NS}$ & $153.9(3.21)$ & $158.0(2.89)$ & $160.7(2.54)^{*}$ \\
BM (kg) & $40.4(2.14)$ & $44.3(1.63)$ & $48.7(1.66)^{*}$ & $\mathrm{~S}$ & $40.5(2.44)$ & $44.6(2.68)$ & $47.7(2.04)^{*}$ \\
LBM (kg) & $33.0(1.64)$ & $35.9(1.42)$ & $39.5(1.39)^{*}$ & $\mathrm{~S}$ & $33.4(1.82)$ & $35.9(1.71)$ & $38.0(1.64)^{*}$ \\
\hline
\end{tabular}

Values are means \pm SEM

$P A$ physical activity, $B M$ total body mass, $L B M$ lean body mass, $N S$ no significant difference between groups IV and V at 13 years, $S$ significant difference between groups between groups IV and V at 13 years

${ }^{*} p<0.05$ between third and first year in different groups
Ventilatory threshold: to determine $\mathrm{V}_{\mathrm{Th}}$ during the maximal incremental step test, we used the respiratory equivalent method (Wasserman et al. 1973) in which $\mathrm{V}_{\mathrm{Th}}$ corresponds to the point at which the respiratory $\mathrm{O}_{2}$ equivalent $\left(\dot{\mathrm{V}}_{\mathrm{E}} / \dot{\mathrm{V}}_{2}\right)$ begins to increase while respiratory $\mathrm{CO}_{2}$ equivalent $\left(\dot{\mathrm{V}}_{\mathrm{E}} / \dot{\mathrm{V}}\right.$ $\mathrm{CO}_{2}$ ) remains stable. Two observers determined $\mathrm{V}_{\text {Th }}$ visually and independently.

\section{Protocol}

All examinations, as well as tests, were carried out in the schools. Clinical examination and an electrocardiogram were carried out at the beginning of the testing procedure. During the clinical examination, the anthropometric measurements were taken. Each subject was then asked to perform a maximal incremental step test in a sitting position on a cycle ergometer (EPS 990, Bodyguard Jonas Ogland AS, Norway). The electrocardiogram was continuously monitored with a cardio scope (Diascope Simonsen and Weel, Denmark). A continuous progressive protocol was used: after $3 \mathrm{~min}$ of warm-up, exercise intensity was increased until exhaustion. For children from age 10.8 to 12 years, the exercise intensity was increased by steps of $20 \mathrm{~W} \cdot \mathrm{min}^{-1}$ and for the other children, by steps of $30 \mathrm{~W} \cdot \mathrm{min}^{-1}$. The children were instructed to maintain a constant pedaling rate of $50 \mathrm{rpm}$ and were actively encouraged throughout the test. The ventilatory measurement was taken during the last $30 \mathrm{~s}$ of each exercise period. $\dot{\mathrm{V}} \mathrm{O}_{2 \max }$ was achieved when three of the following criteria were obtained: a steady heart rate (HR) at a value close to the theoretical maximal HR, a respiratory exchange ratio $(\mathrm{R})$ greater than 1.1 , a constant $\mathrm{V}_{2}$ despite the increased exercise intensity and the impossibility for the subject to maintain a pedaling rate of $50 \mathrm{rpm}$. $\dot{\mathrm{V}}_{\mathrm{Emax}}$ was defined when $\mathrm{VO}_{2 \max }$ was achieved. HR was measured from five recorded ventricular complexes after each effort. All subjects performed the same testing protocol 12 and 24 months later.

Lung function: the measurements of the flow-volume loops and volume-time curve were performed on a digital spirometer (Datalink pulmochart). The maximum expiratory flow (MEF) forced expiratory volume in $1 \mathrm{~s}\left(\mathrm{FEV}_{1}\right)$, and vital capacity (VC) were measured on this occasion.

\section{Statistical analysis}

All values are given as means \pm SEM. One-way analysis of variance was used to measure the annual effects, in all groups, of age on anthropometric characteristics and ventilatory parameters. Concerning boys, the measurements were performed from $11.2 \pm 0.50$ to $13.2 \pm 0.83$ years in group I, from $12.9 \pm 0.71$ to $14.8 \pm 0.89$ years in group II and from $14.9 \pm 0.75$ to $16.9 \pm 0.77$ years in group III. Concerning girls, the measurements were performed from $11.2 \pm 0.61$ to $13.0 \pm 0.57$ years in group IV and from $12.9 \pm 1.11$ to $14.9 \pm 1.72$ years in group V. Student's $t$ test was used to compare the values of parameters between groups I and II (in boys) and IV and V (in girls) at 13 years and between groups II and III (in boys) at 15 years. To study the changes of ventilatory response with age at different percentages of $\dot{\mathrm{V}} \mathrm{O}_{2 \max }(30 \%, 60 \%$ and $90 \%)$, we determined the best regression equation that related each subject's ventilatory response to the percentage of $\dot{\mathrm{V}}_{2 \max }$. The relationships were exponential for $\dot{\mathrm{V}}_{\mathrm{E}}$ and fr and logarithmic for $\mathrm{V}_{\mathrm{T}}$. For each of these relationships, the correlation coefficients were high. We then calculated the values of the different ventilatory parameters for each percentage of $\mathrm{V}_{2 \max }$. The changes of ventilatory response with age at different percentages of $\dot{\mathrm{V}} \mathrm{O}_{2 \max }$ were tested by one-way analysis of variance for repeated measurements completed by a Newman-Keuls test when the ANOVA F ratio was significant $(p<0.05)$. The analyses were carried out on all ventilatory parameters, whether expressed as absolute or relative values, and for all age groups. Values of $p<0.05$ were considered significant throughout the study.

To compare the kinetics of the ventilatory variables as a function of age, sex and at the three different intensities, we used a two-way analysis of variance for repeated measurements completed by a Newman-Keuls test when the ANOVA F ratio was significant $(p<0.05)$. This analysis of variance was used only for groups I (from $11.2 \pm 0.50$ years to $13.2 \pm 0.83$ years) 
and II (from $12.9 \pm 0.71$ years to $14.8 \pm 0.89$ years) in boys and IV (from $11.2 \pm 0.61$ to $13.0 \pm 0.57$ years) and V (from $12.9 \pm 1.11$ to $14.9 \pm 1.72$ years) in girls.

\section{Results}

\section{Anthropometric characteristics and physical activity}

Height, BM and LBM increased $(p<0.05)$ in groups I, II and III for boys (Table 1) and in groups IV and V for girls (Table 2). Concerning boys, no significant differences were observed between groups I and II at 13 years and between groups II and III at 15 years. Differences $(p<0.05)$ were observed in girls between groups IV and V at 13 years, regarding BM and LBM. The time spent in extracurricular physical activities does not change significantly regardless of the sex and age of the subjects (Tables 1 and 2).

\section{Maximal oxygen uptake and ventilatory threshold}

Concerning boys, $\dot{\mathrm{VO}}_{2 \max }$ in $1 . \mathrm{min}^{-1}$ increased $(p<0.05)$ in groups I and II and $\dot{\mathrm{VO}}_{2 \max }$ in ml. $\mathrm{min}^{-1} \cdot \mathrm{kg}^{-1}$ increased $(p<0.05)$ only in group I (Table 3$)$. Concerning girls (Table 4), $\dot{\mathrm{VO}_{2 \max }}$ in $1 . \mathrm{min}^{-1}$ increased $(p<0.05)$ only in group IV and no significant difference was observed in any group regarding $\dot{\mathrm{VO}}_{2 \max }$ in $\mathrm{ml} . \mathrm{min}^{-1} \cdot \mathrm{kg}^{-1} . \mathrm{V}_{\mathrm{Th}}$ in $1 . \mathrm{min}^{-1}$ increased $(p<0.05)$ in groups II and III for boys and in groups IV and V for girls. Concerning boys, differences $(p<0.05)$ were observed at 13 years between groups I and II regarding $\mathrm{V}_{2 \max }$ in $\mathrm{ml} . \mathrm{min}^{-1} . \mathrm{kg}^{-1}$ and at 15 years between groups II and III regarding $\mathrm{V}_{\mathrm{Th}}$ in $\% \mathrm{~V}_{2 \max }$. Concerning girls, a difference $(p<0.05)$ was observed at 13 years between groups IV and $\mathrm{V}$ regarding $\mathrm{V}_{\mathrm{Th}}$ in $1 . \mathrm{min}^{-1}$.

\section{Maximal ventilation and pulmonary function parameters}

Concerning boys (Table 5), $\dot{\mathrm{V}}_{\text {Emax }}, \mathrm{FEV}_{1}$ and VC increased $(p<0.05)$ in groups I, II and III, and MEF increased only in group II. Concerning girls (Table 6), $\dot{\mathrm{V}}_{\mathrm{Emax}}$ increased $(p<0.05)$ in group IV, $\mathrm{FEV}_{1}$, and $\mathrm{VC}$ increased $(p<0.05)$ in groups IV and $\mathrm{V}$ and no significant change was observed regarding MEF. No significant difference was observed for any parameters at 13 years between groups I and II (in boys) and IV and V (in girls) and at 15 years between groups II and III (in boys).

\section{Changes in ventilatory response according to age and exercise intensity}

Expressed in absolute value. Concerning boys (Fig. 1), $\dot{\mathrm{V}}_{\mathrm{E}}$ increased $(p<0.05)$ in groups I and II at all three intensities. In group III, $\dot{\mathrm{V}}_{\mathrm{E}}$ also increased $(p<0.05)$ but only at $60 \%$ and

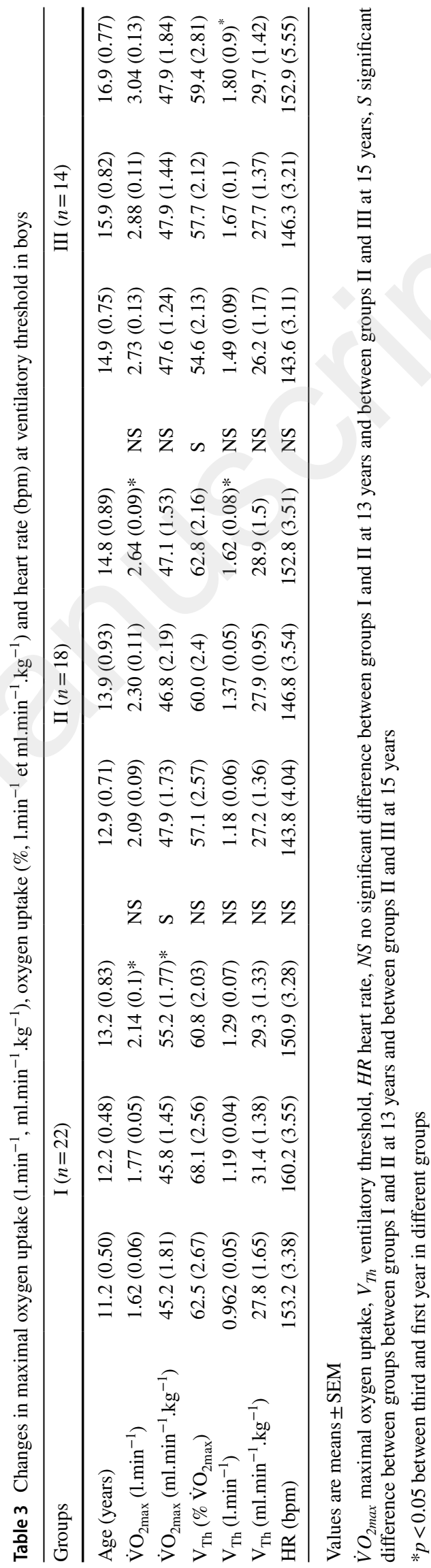


Table 4 Changes in maximal oxygen uptake $\left(1 \cdot \mathrm{min}^{-1}, \mathrm{ml} \cdot \mathrm{min}^{-1} \cdot \mathrm{kg}^{-1}\right)$, oxygen uptake $\left(\%, 1 . \mathrm{min}^{-1}\right.$ et $\left.\mathrm{ml} \cdot \mathrm{min}^{-1} \cdot \mathrm{kg}^{-1}\right)$ and heart rate $(\mathrm{bpm})$ at ventilatory threshold in girls

\begin{tabular}{|c|c|c|c|c|c|c|c|}
\hline \multirow{2}{*}{$\frac{\text { Groups }}{\text { Age (years) }}$} & \multicolumn{3}{|l|}{ IV $(n=7)$} & \multicolumn{4}{|c|}{$\mathrm{V}(n=7)$} \\
\hline & $11.2(0.61)$ & $12.2(0.81)$ & $13.0(0.57)$ & & $12.9(1.11)$ & $13.9(1.11)$ & $14.9(1.72)$ \\
\hline$\dot{\mathrm{V}} \mathrm{O}_{2 \max }\left(1 . \mathrm{min}^{-1}\right)$ & $1.51(0.08)$ & $1.73(0.10)$ & $1.89(0.04)^{*}$ & NS & $1.72(0.10)$ & $1.83(0.13)$ & $1.87(0.08)$ \\
\hline$\dot{\mathrm{V}} \mathrm{O}_{2 \max }\left(\mathrm{ml} \cdot \mathrm{min}^{-1} \cdot \mathrm{kg}^{-1}\right)$ & $37.9(2.42)$ & $39.3(2.47)$ & $39.0(1.63)$ & NS & $43.1(2.69)$ & $41.5(2.81)$ & $39.5(2.34)$ \\
\hline $\mathrm{V}_{\mathrm{Th}}\left(\% \dot{\mathrm{V}} \mathrm{O}_{2 \max }\right)$ & $69.9(3.57)$ & $55.1(2.42)$ & $65.8(2.86)$ & NS & $56.6(4.75)$ & $52.6(3.31)$ & $62.6(3.61)$ \\
\hline $\mathrm{V}_{\mathrm{Th}}\left(1 \cdot \mathrm{min}^{-1}\right)$ & $1.03(0.06)$ & $0.96(0.09)$ & $1.25(0.05)^{*}$ & $S$ & $0.95(0.04)$ & $0.96(0.05)$ & $1.17(0.09)^{*}$ \\
\hline $\mathrm{V}_{\mathrm{Th}}\left(\mathrm{ml} \cdot \mathrm{min}^{-1} \cdot \mathrm{kg}^{-1}\right)$ & $25.6(0.69)$ & $21.8(1.94)$ & $26.2(2.14)$ & NS & $24.1(2.17)$ & $21.8(1.95)$ & $25.0(2.51)$ \\
\hline HR (bpm) & $153.9(3.76)$ & $141.6(6.91)$ & $154.8(7.95)$ & NS & $150.3(6.75)$ & $139.2(4.32)$ & $161.1(5.73)$ \\
\hline
\end{tabular}

Values are means \pm SEM

$\dot{V} O_{2 \max }$ maximal oxygen uptake, $V_{T h}$ ventilatory threshold, $H R$ heart rate, $N S$ no significant difference between groups IV and V at 13 years, $S$ significant difference between groups between groups IV and $\mathrm{V}$ at 13 years

${ }^{*} p<0.05$ between third and first year in different groups

$90 \% \dot{\mathrm{VO}}_{2 \max }$. For $\mathrm{V}_{\mathrm{T}}$, increases $(p<0.05)$ were observed in all three groups and at all three intensities. Finally, no significant change was observed for fr in all three groups and at all three intensities and no significant differences were observed between groups I and II at 13 years and between groups II and III at 15 years for any of the ventilatory parameters. Concerning girls (Fig. 2), $\dot{\mathrm{V}}_{\mathrm{E}}$ increased $(p<0.05)$ in group IV at all three intensities and no significant increase was observed in group $\mathrm{V}$. For $\mathrm{V}_{\mathrm{T}}$, increases $(p<0.05)$ were observed in group IV at all three intensities. In group $\mathrm{V}, \mathrm{V}_{\mathrm{T}}$ also increases $(p<0.05)$ but only at $60 \%$ and $90 \% \dot{V}_{2 \max }$. Finally, fr tended to stabilize in both groups at all three intensities, with no significant change observed. For $\mathrm{V}_{\mathrm{T}}$, differences $(p<0.05)$ were observed between groups IV and $\mathrm{V}$ at 13 years.

Expressed in relative value. Concerning boys, no significant changes were observed for $\dot{\mathrm{V}}_{\mathrm{E}} \cdot \mathrm{kg}^{-1}$, which tends to stabilize in all three groups and at all three intensities (Fig. 3). $\mathrm{V}_{\mathrm{T}} \cdot \mathrm{kg}^{-1}$ increased $(p<0.05)$ in group I at $60 \%$ and $90 \% \mathrm{VO}_{2 \max }$ and in group II but only at $90 \% \dot{\mathrm{VO}}_{2 \max }$. No other significant changes in $\mathrm{V}_{\mathrm{T}} \cdot \mathrm{kg}^{-1}$ were observed in group III and no significant differences between groups I and II at 13 years and between groups II and III at 15 years were observed for any of the ventilatory parameters. Concerning girls, except for a significant difference of $\dot{\mathrm{V}}_{\mathrm{E}} \cdot \mathrm{kg}^{-1}$ and $\mathrm{V}_{\mathrm{T}} \cdot \mathrm{kg}^{-1}$ in group IV at $30 \% \dot{\mathrm{V}} \mathrm{O}_{2 \max }$ between 12 and 13 years, these parameters tend to stabilize in groups IV and V (Fig. 4). A difference $(p<0.05)$ was observed between groups IV and $\mathrm{V}$ at 13 years for $\dot{\mathrm{V}}_{\mathrm{E}} \cdot \mathrm{kg}^{-1}$ at $30 \% \dot{\mathrm{V}}$ $\mathrm{O}_{2 \max }$. No other significant difference was observed at 13 years between groups IV and V.

\section{Changes in ventilatory response according to age, exercise intensity and sex}

Expressed in absolute values. Figure 5 shows that $\dot{V}_{E}$ in boys was significantly higher than that of girls from 11 to
13 years and from 13 to 15 years at either $30 \%(p<0.01)$, $60 \%(p<0.01)$ or $90 \% \mathrm{~V}_{2 \max }(p<0.05)$. No other significant differences were observed for $\mathrm{V}_{\mathrm{T}}$ and fr.

Expressed in relative values. No significant difference was observed for $\mathrm{V}_{\mathrm{T}} \cdot \mathrm{kg}^{-1}$ (Fig. 6). In contrast, $\dot{\mathrm{V}}_{\mathrm{E}} \cdot \mathrm{kg}^{-1}$ was significantly higher $(p<0.05)$ between 11 and 13 years in boys compared to girls at $30 \%, 60 \%$ and $90 \% \dot{\mathrm{VO}}_{2 \max }$. No significant difference between boys and girls was observed between 13 and 15 years.

Important note: for the sake of clarity, some results of the study were included in the "supplementary material" section placed at the end of the manuscript. This supplementary data comprise the changes in ventilation according to carbon dioxide output and the changes in respiratory carbon dioxide equivalent according to oxygen uptake.

\section{Discussion}

The aim of this semi-longitudinal study was to specify in boys and girls the changes, during growth, of submaximal ventilatory response during a maximal incremental test. Our results show significant changes in ventilatory response with age and sex, whether expressed in absolute or relative values.

\section{The effects of age and sex on ventilatory response}

Robinson (1938) showed that $\dot{\mathrm{V}}_{\mathrm{E}}$ increased from 6 to 17 years during a standardized treadmill walk test at constant intensity. The results of Rutenfranz et al. (1981) corroborated those of Robinson (1938). They found that $\dot{V}$ E increased from 12 to 15 years and then stabilized until 17 years. While our results, up to 15 years, agree with those of Rutenfranz et al. (1981), they showed that $\dot{V}_{E}$ increased significantly up to age 17 at the highest exercise intensities (Fig. 1). These results agree with the results of our previous 


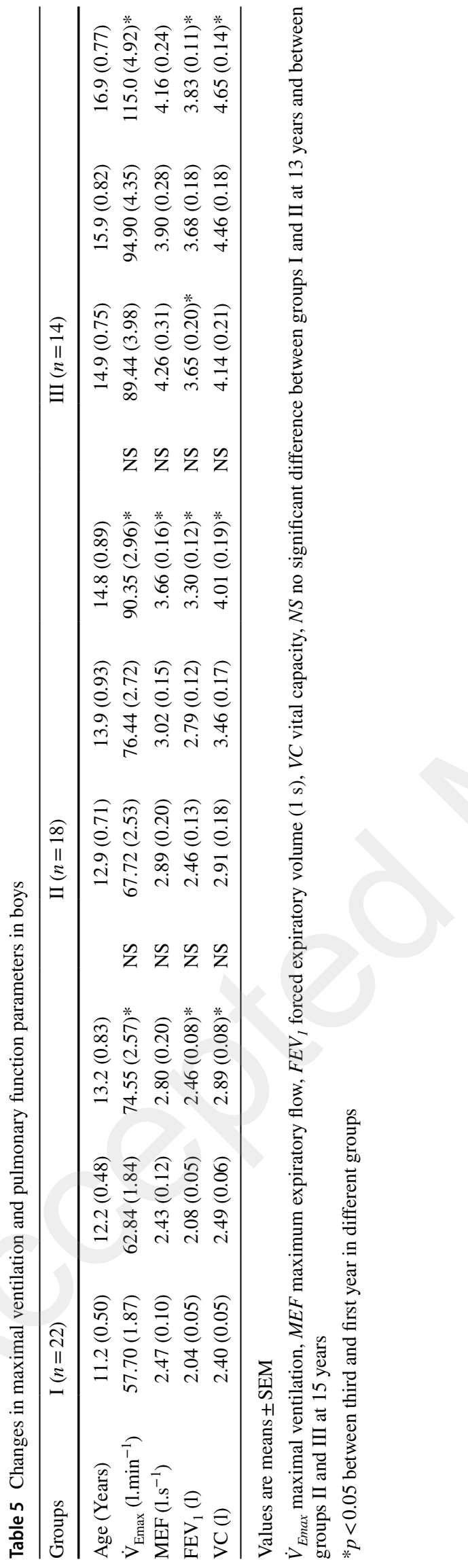

study (Prioux et al. 1997) and those of this study (Table 5), which showed that $\dot{\mathrm{V}}_{\mathrm{Emax}}$ increased significantly between 15 and 17 years (Table 5). However, the $\dot{\mathrm{V}}_{\mathrm{E}}$ values observed by Rutenfranz et al. (1981) at 12, 15 and 17 years seem higher than those of our study at $60 \%$ of $\dot{\mathrm{VO}}_{2 \max }$. These differences can probably be explained by the methodologies used. Indeed, Rutenfranz et al. (1981) measured $\dot{V}$ $\mathrm{E}$ at the same exercise intensity (between 50 and $70 \%$ of $\dot{\mathrm{V}}_{2 \text { max }}$ ) whereas we evaluated $\dot{\mathrm{V}}_{\mathrm{E}}, \mathrm{V}_{\mathrm{T}}$ and fr at three different intensities (below $30 \%$ of $\dot{\mathrm{VO}}_{2 \max }$, around $60 \%$ of $\dot{\mathrm{V}}$ $\mathrm{O}_{2 \max }$ and above $90 \%$ of $\dot{\mathrm{VO}}_{2 \max }$ ). Regardless of the methodological differences discussed previously, the slightly higher exercise intensity in the study by Rutenfranz et al. (1981) compared to ours could also explain the differences of $\dot{V}_{E}$ between our studies. Indeed, at these exercise intensities, the increase in $\dot{V}_{\mathrm{E}}$ is exponential: a small increase in intensity leads to a proportionally larger increase in $\dot{\mathrm{V}}_{\mathrm{E}}$ (Wasserman et al. 1973). Rutenfranz et al. (1981), in their study, were also interested in changes in $\dot{\mathrm{V}}_{\mathrm{E}}$, as a function of age, in girls. These changes appear to be different than for boys. Indeed, their results showed that $\dot{\mathrm{V}}_{\mathrm{E}}$ did not increase for exercise intensities between 65 and $70 \%$ of $\mathrm{VO}_{2 \max }$, and that it remained stable between 12 and 17 years. Similar results were observed by these authors for lower exercise intensities, i.e., between 50 and $65 \%$ of $\dot{\mathrm{VO}}_{2 \max }$. Our results were not fully in agreement with those of Rutenfranz et al. (1981). They showed no significant increase in $\dot{V}_{\mathrm{E}}$ between 13 and 15 years, regardless of exercise intensity, with a significant increase in $\dot{V}_{\mathrm{E}}$ between 11 and 13 years (Fig. 2). However, these results agree with those observed in $\dot{\mathrm{V}}_{\text {Emax }}$ (Table 6). Indeed, they showed that $\dot{\mathrm{V}}_{\text {Emax }}$ increased significantly between 11 and 13 years without any change between 13 and 15 years. Given the relationship between BM, LBM and $\dot{\mathrm{V}}_{\text {Emax }}$ (Mercier et al. 1991; Armstrong and Welsman 2020) it is likely that $\dot{V}_{\text {Emax }}$ did not increase significantly between 13 and 15 years because BM and LBM also did not increase during this period. Finally, regarding the differences in ventilatory response between boys and girls, our results agree with those of Rutenfranz et al. (1981) which showed, from the age of 12 years, a significantly higher $\dot{V}_{\mathrm{E}}$ in boys than girls for the same percentage of $\dot{\mathrm{VO}}_{2 \max }$. Our results also seem to agree with those of Armstrong et al. (1997). The results of this study showed that $\dot{\mathrm{V}}_{\mathrm{E}}$ was significantly higher in boys than in girls, either between 70 and $75 \%$ of $\dot{V}$ $\mathrm{O}_{2 \max }$ or between 80 and $85 \%$ of $\dot{\mathrm{VO}}_{2 \max }$.

Similar to $\dot{V}_{\mathrm{E}}$, few studies have analyzed the changes in $\mathrm{V}_{\mathrm{T}}$ and fr during submaximal intensity exercise. First, while no significant differences were observed between groups I and II at 13 years and between groups II and III at 15 years in boys, significant differences in $\mathrm{V}_{\mathrm{T}}$ were observed at 13 years between groups IV and $\mathrm{V}$ in girls (Fig. 2). Indeed, regardless of exercise intensity, $V_{T}$ at 13 years in group IV was always higher than $\mathrm{V}_{\mathrm{T}}$ in group

377 378 379 380 381 382 383 384 385 386 387 388 389 390 391 392 393 394 395 396 397 398 399 400 401 402 403 404 405 406 407 408 409 410 411 412 413 414 415 416 417 418 419 420 421 422 423 424 425 426 427 428 429 
Table 6 Changes in maximal ventilation and pulmonary function variables in girls

\begin{tabular}{|c|c|c|c|c|c|c|c|}
\hline Groups & IV $(n=7)$ & & & & $\mathrm{V}(n=7)$ & & \\
\hline Age (years) & $11.2(0.61)$ & $12.2(0.81)$ & $13.0(0.57)$ & & $12.9(1.11)$ & $13.9(1.11)$ & $14.9(1.72)$ \\
\hline$\dot{\mathrm{V}}_{\mathrm{Emax}}\left(1 \cdot \mathrm{min}^{-1}\right)$ & $50.42(3.52)$ & $59.16(4.12)$ & $72.25(5.51)^{*}$ & NS & $62.88(4.47)$ & $70.35(3.15)$ & 74.79 (4.66) \\
\hline $\operatorname{MEF}\left(1 . s^{-1}\right)$ & $2.89(0.22)$ & $2.89(0.22)$ & $3.28(0.18)$ & NS & $3.38(0.61)$ & $3.06(0.33)$ & $3.48(0.15)$ \\
\hline $\mathrm{FEV}_{1}(\mathrm{l})$ & $2.35(0.13)$ & $2.39(0.15)$ & $2.66(0.10)^{*}$ & NS & $2.60(0.18)$ & $2.67(0.17)$ & $2.95(0.14)^{*}$ \\
\hline $\mathrm{VC}(\mathrm{L})$ & $2.57(0.13)$ & $2.77(0.20)$ & $3.04(0.10)^{*}$ & NS & $2.87(0.18)$ & $3.14(0.15)$ & $3.48(0.21)^{*}$ \\
\hline
\end{tabular}

Values are means \pm SEM

$\dot{V}_{E \max }$ maximal ventilation, $M E F$ maximum expiratory flow, $F E V_{l}$ forced expiratory volume $(1 \mathrm{~s}), V C$ vital capacity, $N S$ no significant difference between groups IV and $\mathrm{V}$ at 13 years

${ }^{*} p<0.05$ between third and first year in different groups

V. These differences seem to be directly related to anthropometric characteristics. Indeed, BM and LBM are the anthropometric characteristics that best explain the changes in $\dot{\mathrm{V}}_{\text {Emax }}$ and $\mathrm{V}_{\text {Tmax }}$ during growth (Mercier et al. 1991; Armstrong and Welsman 2020) and BM and LBM were significantly higher among 13-year-old girls in group IV (Table 2). However, when $\mathrm{V}_{\mathrm{T}}$ was expressed relatively to BM (Fig. 4) the significant differences disappeared. The significant differences in BM and LBM at 13 years between groups IV and V can probably be explained by the small number of subjects $(n=7)$ in each group of girls and by heterogeneity in pubertal maturation levels between girls in groups IV and V.

Second, the significant increase in $\dot{\mathrm{V}}_{\mathrm{E}}$, up to 17 years in boys, was due to a significant increase in $\mathrm{VC}$, and therefore, $V_{\mathrm{T}}$ (Prioux et al. 1997), while fr tended to decrease (Fig. 1) but without significant change. Robinson's (1938) results showed that $\mathrm{V}_{\mathrm{T}}$ was $430 \mathrm{ml}$ in the youngest children (6 years) and 1.731 in the oldest (17 years). The study by Andersen et al. (1974) corroborated these results. They showed, for a relative intensity between 50 and $60 \%$ of $\dot{V}$ $\mathrm{O}_{2 \max }$, an increase in $\mathrm{V}_{\mathrm{T}}$ from $530 \pm 100$ to $1760 \pm 740 \mathrm{ml}$ in boys and from $460 \pm 120$ to $810 \pm 100 \mathrm{ml}$ in girls. Our study's results appear to be consistent with those outlined above. Indeed, a significant increase was observed in $\mathrm{V}_{\mathrm{T}}$ from 11 to 13 years, 13-15 years, and 15-17 years, regardless of exercise intensity. In girls, $\mathrm{V}_{\mathrm{T}}$ also increased significantly from 11 to 13 years and 13-15 years in group $\mathrm{V}$ except for $\mathrm{V}_{\mathrm{T}}$ between 13 and 15 years at $30 \% \mathrm{~V}_{2 \max }$ (Fig. 2). The fact that the increase in $\mathrm{V}_{\mathrm{T}}$ can be explained by the increase in VC, as indicated above, agrees with (i) the significant increase in $\mathrm{FEV}_{1}$ and VC in boys (Table 5) and girls (Table 6), (ii) the linear relationships between $\mathrm{FEV}_{1}$, $\mathrm{VC}$ and $\mathrm{V}_{\mathrm{Tmax}}$ during growth (Rutenfranz et al. 1981), (iii) the fact that only half of the lung volume capacity is considered during maximal exercise (Rutenfranz et al. 1981) and most importantly (iv) the significant increase in $\mathrm{V}_{\text {Tmax }}$ and $\mathrm{VC}$ up to 17 years, which justifies the stability of the $\mathrm{V}_{\mathrm{Tmax}}$ I VC ratio between 11 and 17 years (Prioux et al. 1997).
Third, the few studies focusing on fr during growth have shown a decrease in fr when age increased. Robinson (1938) observed that fr decreased in boys aged 6-17 years. Data from Andersen et al (1974) were similar to those of Rutenfranz et al. (1981) and confirmed those of Robinson (1938). Rutenfranz et al. (1981) have shown that an exercise carried out at an intensity between 65 and $70 \%$ of $\mathrm{V}_{2 \max }$ in children aged 12-17 years induced a decrease in fr from 39 to 28 breaths. $\mathrm{min}^{-1}$ in boys and from 38 to 26 breaths. $\min ^{-1}$ in girls. These fr values were very close to those we observed at $60 \%$ of $\dot{\mathrm{VO}}_{2 \max }$ especially in boys (Fig. 1). Andersen et al. (1974) showed a decrease in fr, relatively to age, when children aged 8-16 years exercised on a bicycle ergometer at $50-60 \%$ of $\dot{\mathrm{VO}}_{2 \max }$ intensity or $70-80 \%$ of $\dot{\mathrm{V}}$ $\mathrm{O}_{2 \max }$ intensity. Rowland and Cunningham (1997) showed that fr decreased from 45 to 36 breaths. $\mathrm{min}^{-1}$ in children aged 9-13 years. Finally, Ondrak and McMurray (2006) found that fr decreased with age regardless of exercise intensity. The results we observed in boys (Fig. 1) were consistent with those in the literature. Indeed, although not significant, fr tended to decrease in all age groups and for each intensity. A full longitudinal study conducted from 11 to 17 years of age could have shown a significant decrease for this parameter. The results observed in girls are more difficult to interpret. Indeed, Fig. 2 seems to indicate a tendency of fr to stabilize during growth. However, the comparison of fr kinetics as a function of sex (Fig. 5) showed no significant difference between girls and boys, which was consistent with the literature (Robinson 1938; Andersen et al. 1974; Rutenfranz et al. 1981). The trend of fr, with advancing age, would, therefore, be to decrease for both girls and boys.

\section{The effects of age, sex, and body weight on ventilatory response}

Height is the simplest parameter to measure when evaluating growth. It was, therefore, naturally proposed as a determining factor in the ventilatory response (Mercier et al. 1991; Rutenfranz et al. 1981; Rowland 1996). However, 

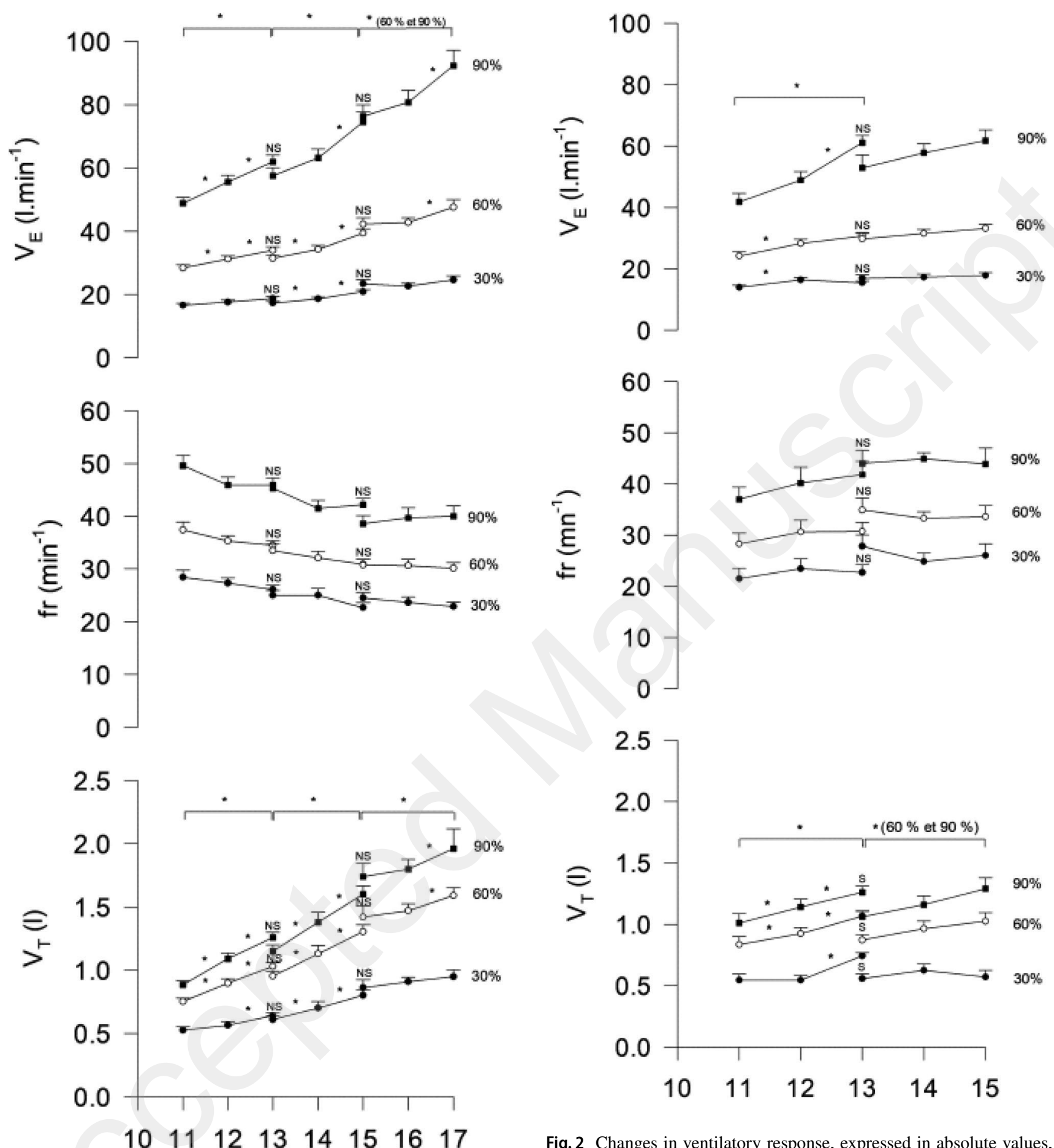

Fig. 2 Changes in ventilatory response, expressed in absolute values, as a function of exercise intensity in girls. $\dot{V}_{E}$ ventilation, fr respiratory frequency, $V_{T}$ tidal volume; $30 \%, 60 \%$ and $90 \%$ : exercise intensity expressed in $\% \dot{\mathrm{VO}}_{2 \max }$; values are means $\pm \mathrm{SEM} ; * p<0.05 ; N S$ no significant difference between groups IV and $\mathrm{V}$ at 13 years as a function of exercise intensity in boys. $\dot{V}_{E}$ ventilation, $f r$ respiratory frequency, $V_{T}$ tidal volume; $30 \%, 60 \%$ and $90 \%$ : exercise intensity expressed in $\% \dot{\mathrm{VO}}_{2 \max }$; values are means $\pm \mathrm{SEM} ; * p<0.05 ; N S$ no significant difference between groups I and II at 13 years and between groups II and III at 15 years

the systematic use of height as a determinant of $V_{\text {Emax }}$, recommended by Rowland, (1996), is relativized by the study of Mercier et al., (1991). Indeed, for these authors, $\mathrm{BM}$ and LBM are the anthropometric characteristics that best explain the variations in $\mathrm{V}_{\mathrm{Emax}}$ and $\mathrm{V}_{\mathrm{T} \max }$ with 

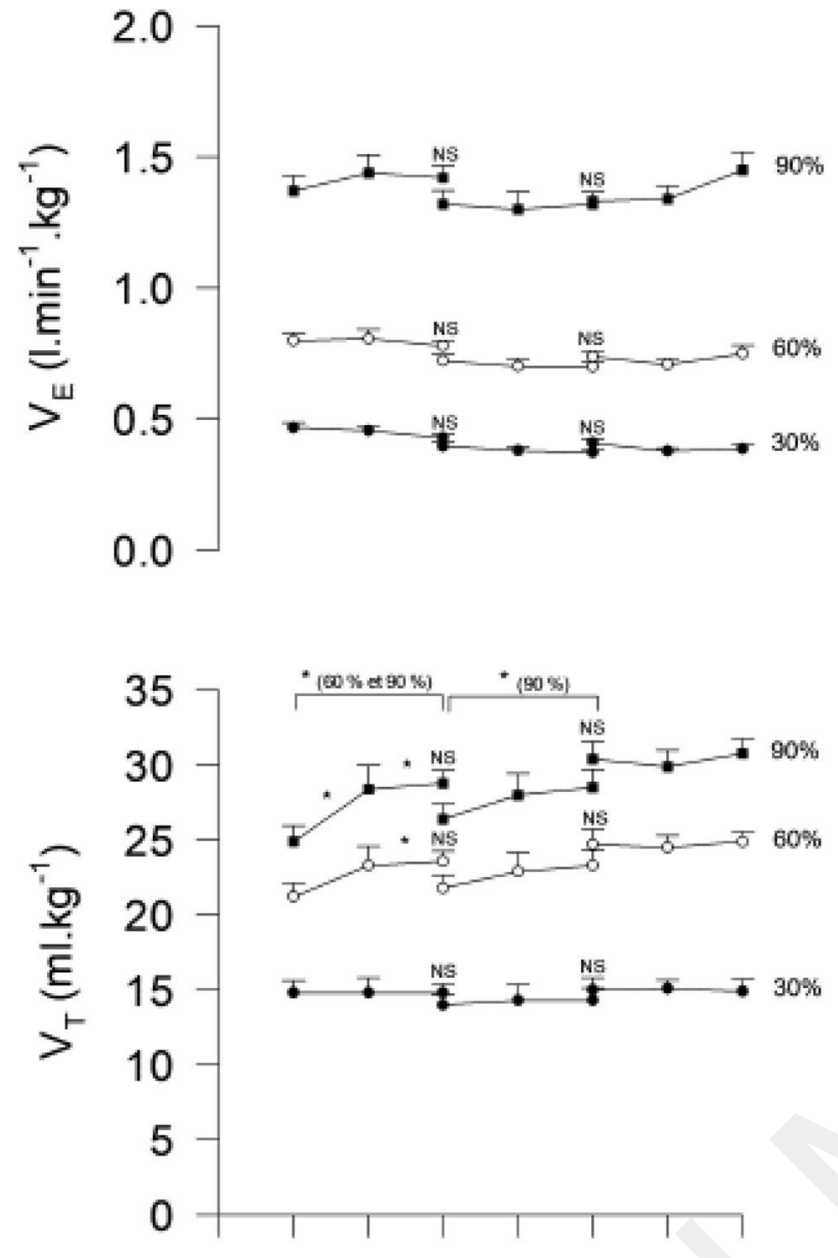

\section{$\begin{array}{llllllll}10 & 11 & 12 & 13 & 14 & 15 & 16 & 17\end{array}$ Age (years)}

Fig. 3 Changes in ventilatory response, expressed in relative values, as a function of exercise intensity in boys. $\dot{V}_{E}$ ventilation, $V_{T}$ tidal volume; $30 \%, 60 \%$ and $90 \%$ : exercise intensity expressed in $\% \mathrm{VO}_{2 \max }$; values are means $\pm \mathrm{SEM} ;{ }^{*} p<0.05 ; N S$ no significant difference between groups I and II at 13 years and between groups II and III at 15 years growth. Thus, studies such as ours, which propose $V_{E \max }$ and $\mathrm{V}_{\text {Tmax }}$ values only corrected by BM are not far from reality (Armstrong and Welsman 2020). Likewise, the use of BM also makes it possible to compare our values with those in the literature. Robinson (1938) found a decrease in $\dot{\mathrm{V}}_{\mathrm{E}} \cdot \mathrm{kg}^{-1}$ for boys aged 6-17 years. Similar results have been observed by Rowland and Cunningham (1997) who indicated that $\dot{\mathrm{V}}_{\mathrm{E}} \cdot \mathrm{kg}^{-1}$ decreased with age without any difference between boys and girls. More recently, Ondrak and McMurray (2006) found that $\dot{\mathrm{V}}_{\mathrm{E}} \cdot \mathrm{kg}^{-1}$ decreased with age, regardless of exercise intensity, in children 8-18 years. Our results do not coincide with those of the two previous studies. Indeed, $\dot{\mathrm{V}}_{\mathrm{E}} \cdot \mathrm{kg}^{-1}$ remained stable during growth
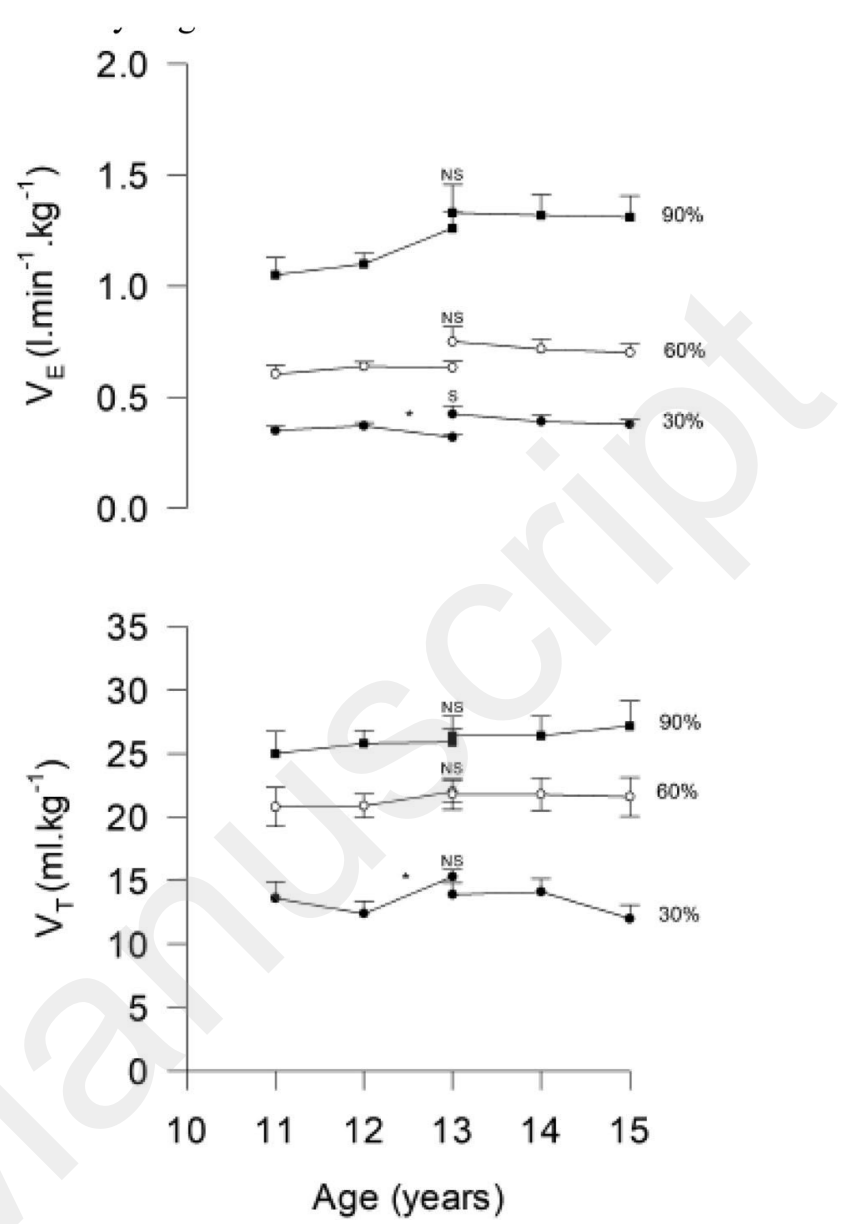

Fig. 4 Changes in ventilatory response, expressed in relative values, as a function exercise intensity in girls. $\dot{V}_{E}$ ventilation, $V_{T}$ tidal volume; $30 \%, 60 \%$ and $90 \%$ : exercise intensity expressed in $\% \dot{\mathrm{VO}}_{2 \max }$; values are means $\pm \mathrm{SEM} ;{ }^{*} p<0.05 ; N S$ no significant difference between groups IV and $\mathrm{V}$ at 13 years

in boys (Fig. 3) and girls (Fig. 4) with significantly higher values in boys between 11 and 13 years, regardless of exercise intensity (Fig. 6). However, the comparison of our results with previous studies is questionable. Firstly, in the studies of Robinson et al. (1938) and Ondrak and McMurray, (2006) the exercise intensities are expressed in absolute values. Hence, each workload may have elicited greater ventilatory responses in the younger and smaller participants, compared to the older and larger participants. Secondly, Rowland and Cunningham (1997) focused on a small number of children (11 boys and 9 girls) and a relatively small age range (9-13 years). Thus, the variability in exercise protocols, the use of different submaximal intensities, the lack of evaluation of the subjects' body composition and level of physical activity may contribute to the variability of the results between the different studies. The $\dot{V}_{\mathrm{E}} \cdot \mathrm{kg}^{-1}$ values proposed in our study can only be used as a guideline when interpreting exercise testing 
Fig. 5 Changes in ventilatory response, expressed in absolutes values, as a function of exercise intensity and sex. $\dot{V}_{E}$ ventilation, $f r$ respiratory frequency; $V_{T}$ tidal volume; $30 \%, 60 \%$ and $90 \%$ : exercise intensity expressed in $\% \dot{\mathrm{VO}}{ }_{2 \max } ; \dot{\mathrm{VO}}_{2 \max }$ : maximum oxygen uptake; values are means $\pm \mathrm{SEM} ; N S$ no significant difference between groups boys and girls
Fig. 6 Changes in ventilatory response, expressed in relative values, as a function of exercise intensity and sex. $\dot{V}_{E}$ ventilation, $V_{T}$ tidal volume; $30 \%, 60 \%$ and $90 \%$ : exercise intensity expressed in $\% \dot{\mathrm{VO}}{ }_{2 \max } ; \dot{\mathrm{VO}}_{2 \max }$ : maximum oxygen uptake; values are means $\pm \mathrm{SEM} ; N S$ no significant difference between groups boys and girls
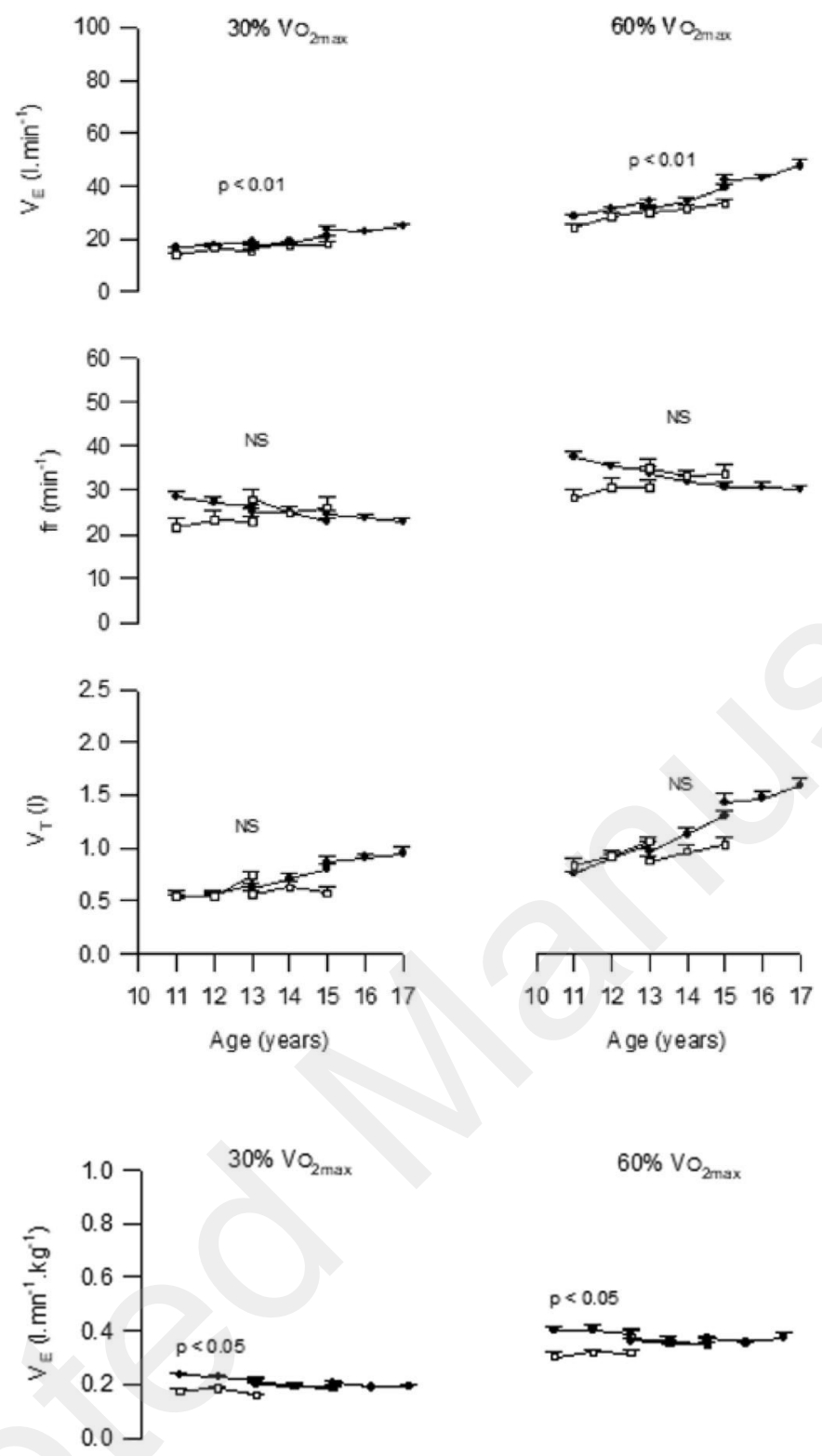

$\begin{array}{llllllll}10 & 11 & 12 & 13 & 14 & 15 & 16 & 17\end{array}$ A ge (years)

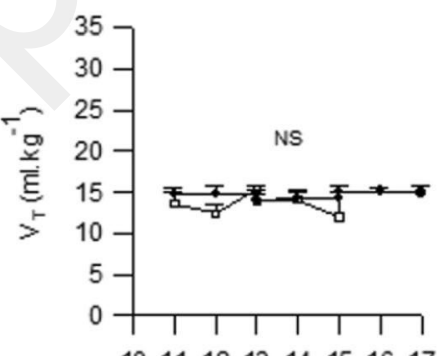

$\begin{array}{llllllll}10 & 11 & 12 & 13 & 14 & 15 & 16 & 17\end{array}$

Age (y ears)

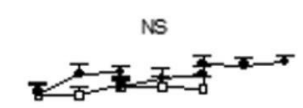

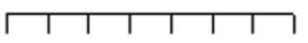

$\begin{array}{llllllll}10 & 11 & 12 & 13 & 14 & 15 & 16 & 17\end{array}$

Age (y ears)

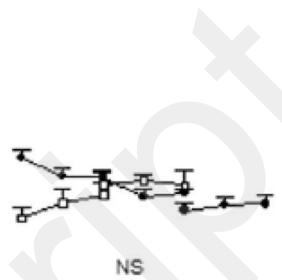

NS
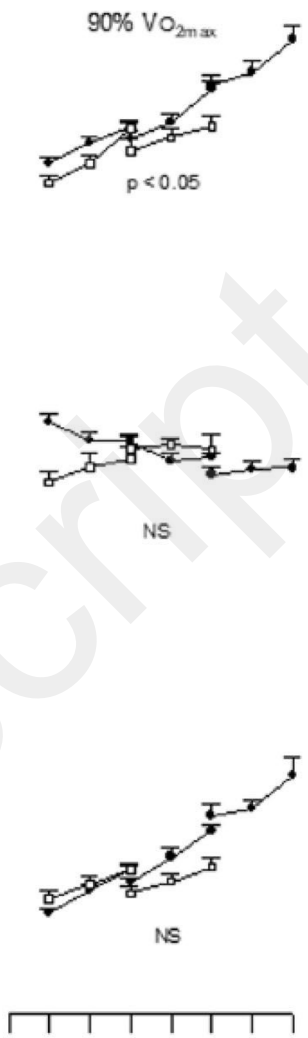

$\begin{array}{llllllll}10 & 11 & 12 & 13 & 14 & 15 & 16 & 17\end{array}$

Age (years)

$90 \% \mathrm{Vo}_{2 \max }$

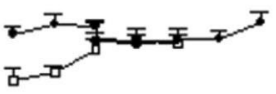

$p<0.05$

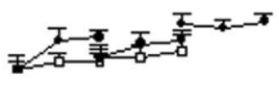

NS

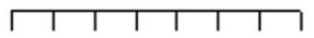

$\begin{array}{llllllll}10 & 11 & 12 & 13 & 14 & 15 & 16 & 17\end{array}$

Age (years) in children. More complete analyses should be carried out on the changes of ventilatory response at submaximal intensities according to, for example, mechanical power developed relative to the child's total mass.
Concerning $\mathrm{V}_{\mathrm{T}} \cdot \mathrm{kg}^{-1}$, Robinson (1938) found a small increase when comparing to age: $\mathrm{V}_{\mathrm{T}} \cdot \mathrm{kg}^{-1}$ increased from $0.0211 . \mathrm{min}^{-1} \cdot \mathrm{kg}^{-1}$ at 6 years to $0.0251 . \mathrm{min}^{-1} \cdot \mathrm{kg}^{-1}$ at 17 years. More recently, Ondrak and McMurray (2006) 
showed that $\mathrm{V}_{\mathrm{T}} \cdot \mathrm{kg}^{-1}$ decreased with age, regardless of exercise intensity, in children aged $8-18$ years. These results are not in agreement with those of Rowland and Cunningham (1997). Indeed, these authors found no significant changes for $\mathrm{V}_{\mathrm{T}} \cdot \mathrm{kg}^{-1}$ in boys aged 9-13 years. Our results in boys showed a significant increase in $\mathrm{V}_{\mathrm{T}} \cdot \mathrm{kg}^{-1}$ from 11 to 13 years at $60 \%$ and $90 \%$ of $\dot{\mathrm{VO}}_{2 \max }$ and from 13 to 15 years at $90 \%$ of $\dot{\mathrm{V}}_{2 \max }$ (Fig. 3). From 15 years of age in group III and up to the age of 17 years, $\mathrm{V}_{\mathrm{T}} \cdot \mathrm{kg}^{-1}$ no longer increased. These results suggest that, up to 15 years, the increase in $\mathrm{V}_{\mathrm{T}}$ is greater than the increase in $\mathrm{BM}$ at high intensities $(60 \%$ and $90 \%$ of $\dot{\mathrm{VO}}_{2 \max }$ ). BM may, therefore, not be the best anthropometric parameter to consider when studying the changes of $\mathrm{V}_{\mathrm{T}}$ during growth. The use of LBM appears to be more appropriate (Mercier et al. 1991; Amstrong and Welsman 2020). However, these results also assume that parameters, other than anthropometric characteristics, can influence the changes of $\mathrm{V}_{\mathrm{T}} \cdot \mathrm{kg}^{-1}$ during growth. This does not seem to be the case for girls. Indeed, except for a significant increase in $\mathrm{V}_{\mathrm{T}} \cdot \mathrm{kg}^{-1}$ between 12 and 13 years at $30 \%$ of $\dot{\mathrm{VO}}_{2 \max }$, our results showed a remarkable stability of this parameter during growth (Fig. 4). Finally, the evolution of $\mathrm{V}_{\mathrm{T}} \cdot \mathrm{kg}^{-1}$ during growth appears to be independent of sex, since no difference in $\mathrm{V}_{\mathrm{T}} \cdot \mathrm{kg}^{-1}$ was observed between boys and girls (Fig. 6).

\section{Strengths and limitations}

Although breathing pattern data are presented in our study and helps to explain the changes in ventilation during growth, we have not fully considered how ventilatory control may change with age. It would be interesting (i) to add an index of operating lung volume (i.e., expiratory and inspiratory reserve volume) and (ii) to report $\mathrm{P}_{\mathrm{a}} \mathrm{CO} 2$ or more practically $\mathrm{P}_{\mathrm{ET}} \mathrm{CO} 2$ data. Indeed, these data would provide further detail regarding exercise ventilatory mechanics (i.e., presence of dynamic hyperinflation) and ventilatory control (i.e., estimates of dead space and alveolar ventilation). In addition, we should have used a more appropriate experimental model, such as a real longitudinal study from 11 to 15 years in girls and from 11 to 17 years in boys, to analyze changes in ventilatory responses at submaximal exercise intensities during the growth spurt period (Amstrong and Welsman 2020). Finally, the sample size differs substantially between boys and girls. Indeed, we have 54 healthy untrained boys against only 14 healthy untrained girls. Moreover, we have collected data from 11 to 17 years in boys and only from 11 to 15 years in girls. Despite the validity of our statistical analyses, it would be interesting to conduct other studies with more subjects of both sexes and over a longer period, especially for girls, so that (i) the data can reflect the general pediatric population in France and (ii) to use these data as age-specific normative values for exercise performance.

\section{Conclusion}

At submaximal intensities, $\dot{\mathrm{V}}_{\mathrm{E}}$, expressed in absolute values, increases between 11 and 17 years in boys and only between 11 and 13 years in girls. Increases in VC, and therefore, in $\mathrm{V}_{\mathrm{T}}$, is the main reason for $\dot{\mathrm{V}}_{\mathrm{E}}$ increases during growth. $\dot{V}_{E}$ in boys is higher than $\dot{V}_{E}$ in girls regardless of age and exercise intensity. $\dot{\mathrm{V}}_{\mathrm{E}} \cdot \mathrm{kg}^{-1}$ is stable in boys and girls whatever the intensity of exercise with significantly lower values in girls compared to boys between 11 and 13 years, regardless of exercise intensity. In boys, $\mathrm{V}_{\mathrm{T}} \cdot \mathbf{A 0 7} \mathbf{9}$ $\mathrm{kg}^{-1}$ increases significantly from 11 to 15 years and then 610 stabilizes until the age of 17 years while $\mathrm{V}_{\mathrm{T}} \cdot \mathrm{kg}^{-1}$ tends to 611 stabilize during growth in girls with no significant differ- $\quad 612$ ence of $\mathrm{V}_{\mathrm{T}} \cdot \mathrm{kg}^{-1}$ between boys and girls regardless of age $\quad 613$ and exercise intensity.

Supplementary Information The online version contains supplementary material available at https://doi.org/10.1007/s00421-021-04776-4.

Acknowledgements Supported by the Institut National de la Recherche Scientifique (Grant No. 486 023).

Author contributions All the authors contributed to the study conception and design. Material preparation, data collection and analysis were performed by Fenfen Zhou, Jacques Prioux, and Xiaojian Yin. The first draft of the manuscript was written by Fenfen Zhou with support from Jacques Prioux, Kilian Phillipe, Aya Houssein, Steven Gastinger and all the authors commented on previous versions of the manuscript. All the authors provided critical feedback and helped shape the research, analysis and manuscript.

\section{References}

Andersen K, Seliger V, Rutenfranz J, Messel S (1974) Physical performance capacity of children in Norway. III. Respiratory responses to graded exercise loadings-population parameters in a rural community. Eur J Appl Physiol 33:265-274

Armstrong N, Welsman J (2020) Influence of sex-specific concurrent changes in age, maturity status, and morphological covariates on the development of peak ventilatory variables in 10-17-yearolds. Eur J Appl Physiol 121:1-10. https://doi.org/10.1007/ s00421-020-04569-1

Armstrong N, Kirby BJ, McManus AM, Welsman JR (1997) Prepubescents' ventilatory responses to exercise with reference to sex and body size. Chest 112:1554-1560. https://doi.org/10.1378/ chest.112.6.1554

Boule M, Gaultier C, Girard F (1989) Breathing pattern during exercise in untrained children. Respir Physiol 75:225-233. https://doi.org/ 10.1016/0034-5687(89)90066-2

Burstein DS, McBride MG, Min J, Paridon AA, Perelman S, Huffman EM, O'Malley S, Del Grosso J, Groepenhoff H, Paridon SM, Brothers JA (2020) Normative values for cardiopulmonary exercise stress testing using ramp cycle ergometry in children and adolescents. J Pediatr 229:61-69. https://doi.org/10.1016/j.jpeds. 2020.09.018 
Calbet JA, Lundby C (2009) Air to muscle $\mathrm{O}_{2}$ delivery during exercise at altitude. High Alt Med Biol 10:123-134. https://doi.org/10. 1089/ham.2008.1099

Durnin J, Rahaman MM (1967) The assessment of the amount of fat in the human body from measurements of skinfold thickness. Br J Nutr 21:681-689. https://doi.org/10.1079/BJN19670070P

Holley K, MacNabb CM, Georgiadis P, Minasyan H, Shukla A, Mathews D (2016) Monitoring minute ventilation versus respiratory rate to measure the adequacy of ventilation in patients undergoing upper endoscopic procedures. J Clin Monit Comput 30:33-39. https://doi.org/10.1007/s10877-015-9674-y

Marinov B, Mandadzhieva S, Kostianev S (2007) Oxygen-uptake efficiency slope in healthy 7-to 18-year-old children. Pediatr Exerc Sci 19:159-170. https://doi.org/10.1123/pes.19.2.159

Matecki S, Prioux J, Jaber S, Hayot M, Prefaut C, Ramonatxo M (2003) Respiratory pressures in boys from 11-17 years old: a semilongitudinal study. Pediatr Pulmonol 35:368-374. https://doi.org/10. 1002/ppul.10274

Mercier J, Varray A, Ramonatxo M, Mercier B, Préfaut C (1991) Influence of anthropometric characteristics on changes in maximal exercise ventilation and breathing pattern during growth in boys. Eur J Appl Physiol 63:235-241. https://doi.org/10.1007/bf002 33854

O’Donnell DE, Oral J, Webb KA, Laveneziana P, Jensen D (2009) Mechanisms of activity-related dyspnea in pulmonary diseases. Respir Physiol Neurobiol 167(1):116-132. https://doi.org/10. 1016/j.resp.2009.01.010

Ondrak KS, McMurray RG (2006) Exercise-induced breathing patterns of youth are related to age and intensity. Eur J Appl Physiol 98:88-96. https://doi.org/10.1007/s00421-006-0248-z

Prado DML, Braga AMFW, Rondon MUP, Azevedo LF, Matos LDNJ, Negrao CE, Trombetta IC (2010) Cardiorespiratory responses during progressive maximal exercise test in healthy children. Arq Bras Cardiol 94(4):464-470. https://doi.org/10.1590/S0066782X2010005000007

Prioux J, Ramonatxo M, Mercier J, Granier P, Mercier B, Prefaut C (1997) Changes in maximal exercise ventilation and breathing pattern in boys during growth: a mixed cross-sectional longitudinal study. Acta Physiol Scand 161:447-458. https://doi.org/10.1046/j. 1365-201X.1997.00245.x
Robinson S (1938) Experimental studies of physical fitness in relation to age. Arbeitsphysiologie 10:251-323. https://doi.org/10.1007/ BF02011412

Rowland TW (1996). Response to endurance exercise: ventilation. In: Developmental exercise physiology. Ed. Human Kinetics p. 141-157.

Rowland TW, Cunningham LN (1997) Development of ventilatory responses to exercise in normal white children: a longitudinal study. Chest 111:327-332. https://doi.org/10.1378/chest.111.2. 327

Rutenfranz J, Andersen KL, Seliger V, Klimmer F, Ilmarinen J, Ruppel M, Kylian H (1981) Exercise ventilation during the growth spurt period: comparison between two European countries. Eur J Pediatr 136:135-142. https://doi.org/10.1007/BF00441915

Tanner JM (1962) Growth at adolescence. Blackwell, Oxford

Wasserman K, Van Kessel AL, Burton G (1967) Interaction of physiological mechanisms during exercise. J Appl Physiol 22:71-85

Wasserman K, Whipp BJ, Koyl S, Beaver W (1973) Anaerobic threshold and respiratory gas exchange during exercise. J Appl Physiol 35:236-243. https://doi.org/10.1152/jappl.1973.35.2.236

Wasserman K, Whipp BJ, Casaburi R (1986) Respiratory control during exercise. In: Handbook of Physiology: The Respiratory System, a. Control of breathing, Sec. 3, Vol. II, N.S. Cherniak and J.G. Widdicombe (Eds). Bethesda, MD: Am Physiol Soc 595-620

Weiner JS, Lourie JA (1981) Practical human biology. Academic Press, New York

Whipp BJ, Pardy RL (1986) Breathing during exercise. In: Handbook of physiology; the respiratory system, mechanism of breathing. Sect 3, part 2:605-629

Zhang YY, Wasserman K, Sietsema KE, Ben-Dov I, Barstow TJ, Mizumoto G, Sullivan CS (1993) O2 uptake kinetics in response to exercise: a measure of tissue anaerobiosis in heart failure. Chest 103:735-741. https://doi.org/10.1378/chest.103.3.735

Publisher's Note Springer Nature remains neutral with regard to jurisdictional claims in published maps and institutional affiliations. 